Check for updates

Cite this: RSC Adv., 2020, 10, 14670

\title{
The design and growth of peanut-like CuS/BiVO composites for photoelectrochemical sensing $\dagger$
}

\begin{abstract}
Yang Yang, $t^{\mathrm{ab}}$ Junting Liang, $\sharp^{\mathrm{a}}$ Wenwen Jin, ${ }^{\mathrm{c}}$ Yingyue $\mathrm{Li},{ }^{\mathrm{c}}$ Menghui Xuan, ${ }^{\mathrm{c}}$ Shijie Wang, ${ }^{c}$ Xiaoqian Sun, ${ }^{c}$ Chuanliang Chen ${ }^{\star a}$ and Jianhua Zhang $\mathbb{D}^{* c}$

In this study, the CuS/BiVO $4-X$ (where $X$ represents the mass percentage of CuS associated with CuS/BiVO ; $X=2 \%, 5 \%$ and $7 \%) \mathrm{p}-\mathrm{n}$ heterostructures were fabricated using a two-step hydrothermal method. The structural and morphological features were ascertained in great detail using several physical characterization processes. According to the results of the photoelectrochemical (PEC) experimental processes, the PEC properties of $\mathrm{CuS} / \mathrm{BiVO}_{4}-5 \%$ were much more obvious as compared to those of pure $\mathrm{BiVO}_{4}, \mathrm{CuS}$ and $\mathrm{CuS} / \mathrm{BiVO}_{4}-\mathrm{X}$. Moreover, the photoluminescence (PL) and UV-vis diffuse reflection spectra (DRS) affirmed that the $\mathrm{CuS} / \mathrm{BiVO}_{4}-5 \%$ demonstrates an excellent capacity for absorbing visible light and low electron recombination rate as compared with the other composites. Accordingly, PEC sensors with $\mathrm{CuS} / \mathrm{BiVO}_{4}-5 \%$ were fabricated for the detection of dopamine (DA) and bisphenol A (BPA) with outstanding selectivity and stability. For DA, it implied a broad linear range from $0.01-10 \mu \mathrm{M}$ and 10-120 $\mu \mathrm{M}$, and for BPA, the broad linear range was 0.01-90 $\mu \mathrm{M}$. Thus, the PEC sensor has significant potential application when it comes to DA and BPA detection.
\end{abstract}

Received 11th February 2020

Accepted 18th March 2020

DOI: $10.1039 / \mathrm{dOra01307b}$

rsc.li/rsc-advances semiconductor materials with easy fabrication and broad optical response should be developed.

To date, photocatalysts with a bismuth-system have found application in PEC study, including $\mathrm{BiVO}_{4}, \mathrm{Bi}_{2} \mathrm{MoO}_{6}, \mathrm{Bi}_{2} \mathrm{WO}_{6}$, $\mathrm{BiPO}_{4}$ and so on. ${ }^{15-18}$ Bismuth-system oxides, which are composed of $6 \mathrm{~s} \mathrm{Bi}$ orbitals and $2 \mathrm{p}$ oxygen orbitals, display outstanding electrical and optical characteristics. ${ }^{19}$ Moreover, they enjoy several popular strengths, e.g., abundance, low toxicity, and low cost. ${ }^{20}$ Among them, bismuth vanadate $\left(\mathrm{BiVO}_{4}\right)$, an n-type semiconductor, is regarded to be a photocatalyst that is full of potential due to its narrow band gap (2.4 $\mathrm{eV}),{ }^{21}$ together with its wide use in photoelectrocatalytic water splitting, ${ }^{22}$ PEC sensors ${ }^{23}$ and PEC $\mathrm{CO}_{2}$ reduction. ${ }^{24}$ However, it is not efficient in energy conversion due to the rate of rapid charge recombination. ${ }^{25}$ The combination of other semiconductor elements and $\mathrm{BiVO}_{4}$ will help to improve the electron transfer efficiency and facilitate electron-hole pair separation, thus enhancing the energy conversion efficiency. ${ }^{\mathbf{2 6}}$

In recent years, sulfide-based photocatalysts $\left(\mathrm{MoS}_{2}, \mathrm{WS}_{2}\right.$, CdS et al.) have become the focus of most exploration as they enjoy a relatively narrow band gap as well as a greater range of light absorption. ${ }^{27-29}$ Copper sulfide (CuS), a promising p-type semiconductor, can absorb and utilize ultraviolet (UV) and visible light due to its small band gap $(2.1 \mathrm{eV}) .{ }^{30,31}$ The heterojunction formed between a p-type and an n-type semiconductor is capable of enhancing the ability to absorb visible light as well as facilitating the separation process of charge carriers. ${ }^{32,33}$ As such, we designed a complex of $\mathrm{BiVO}_{4}$ and CuS to improve the PEC performance. 
In this paper, we adopted a two-step hydrothermal method and successfully synthesized $\mathrm{CuS} / \mathrm{BiVO}_{4}$ heterojunction composites. The PEC activity was assessed by detecting DA and BPA under visible light irradiation. The results demonstrate that the $\mathrm{CuS} / \mathrm{BiVO}_{4}$ composites developed greater PEC efficiency as compared with $\mathrm{CuS}$ and $\mathrm{BiVO}_{4}$, and showed outstanding selectivity, low detection limits and a wide linear range for detecting DA and BPA. According to the results, the sensors with $\mathrm{CuS} / \mathrm{BiVO}_{4}$ have great potential for applications in the practical detection of DA and BPA.

\section{Experimental}

\section{Reagents}

All reagents were of analytical grade and were used without further purification. Bismuth nitrate pentahydrate $\left(\mathrm{Bi}\left(\mathrm{NO}_{3}\right)_{3}\right.$ $\left.\cdot 5 \mathrm{H}_{2} \mathrm{O}\right)$, ammonium metavanadate $\left(\mathrm{NH}_{4} \mathrm{VO}_{3}\right)$, copper nitrate trihydrate $\left(\mathrm{Cu}\left(\mathrm{NO}_{3}\right)_{2} \cdot 3 \mathrm{H}_{2} \mathrm{O}\right)$, sodium thiosulfate pentahydrate $\left(\mathrm{Na}_{2} \mathrm{~S}_{2} \mathrm{O}_{3} \cdot 5 \mathrm{H}_{2} \mathrm{O}\right)$ and ethylene glycol (EG) were purchased from Sinopharm Chemical Reagent Co. Ltd. (https:// www.sinoreagent.com). Dopamine was purchased from Aladdin Chemical Reagent Co. Ltd. (https://www.aladdine.com). Human serum samples were purchased from the People's Hospital of Zhengzhou University, Clinical Bioinformatics Experimental Center.

\section{Preparation of the $\mathrm{CuS} / \mathrm{BiVO}_{4}$ heterojunction}

The $\mathrm{CuS} / \mathrm{BiVO}_{4}$ heterojunction was prepared by a two-step hydrothermal method. To synthesize $\mathrm{BiVO}_{4}, \mathrm{Bi}\left(\mathrm{NO}_{3}\right)_{3} \cdot 5 \mathrm{H}_{2} \mathrm{O}$ and $\mathrm{NH}_{4} \mathrm{VO}_{3}$ were dissolved in a mixture solution of EG and hot water. The solution was transferred into a $100 \mathrm{~mL}$ Teflon-lined stainless autoclave and kept at $120{ }^{\circ} \mathrm{C}$ for $12 \mathrm{~h}$. The prepared $\mathrm{BiVO}_{4}$ powder was dispersed in distilled water by ultrasonication for $30 \mathrm{~min}$, and appropriate amounts of $\mathrm{Cu}\left(\mathrm{NO}_{3}\right)_{2}$ $\cdot 3 \mathrm{H}_{2} \mathrm{O}$ and $\mathrm{Na}_{2} \mathrm{~S}_{2} \mathrm{O}_{3} \cdot 5 \mathrm{H}_{2} \mathrm{O}$ were added successively. After the addition of $10 \mathrm{~mL}$ of ethanol to the above solution under stirring, the mixture was transferred to a $50 \mathrm{~mL}$ Teflon-lined stainless autoclave and heated at $200{ }^{\circ} \mathrm{C}$ for $12 \mathrm{~h}$. Finally, the product was cleaned and then dried at $60{ }^{\circ} \mathrm{C}$. The $\mathrm{CuS} / \mathrm{BiVO}_{4}$ heterojunction composed of different $\mathrm{CuS}$ contents was labeled as $\mathrm{CuS} / \mathrm{BiVO}_{4}-X$, where $X$ represents the mass percentage of $\mathrm{CuS}$ associated with the $\mathrm{CuS} / \mathrm{BiVO}_{4}$ heterojunction. For comparison, different $\mathrm{CuS} / \mathrm{BiVO}_{4}$ heterojunctions having different mass ratios of CuS ( $2 \mathrm{wt} \%, 5 \mathrm{wt} \%$ and $7 \mathrm{wt} \%$ ) were also prepared.

\section{Electrochemical experiments}

All electrochemical experimental processes were conducted using a three-electrode system (CHI 660E). Pt wire and a saturated calomel electrode (SCE) played the roles of the counter electrode and reference electrode, respectively. We performed electrochemical impedance spectroscopy (EIS) in the frequency range of 1 to $1000000 \mathrm{~Hz}$ in $0.1 \mathrm{M}$ phosphate buffer (pH 7.0) produced by mixing the stock solutions of $\mathrm{Na}_{2} \mathrm{HPO}_{4}$ and $\mathrm{NaH}_{2} \mathrm{PO}_{4}$. The indium tin oxide (ITO) glass served as the

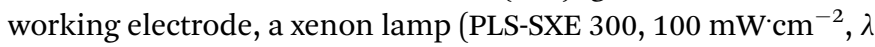
$\geq 420 \mathrm{~nm}$ ) was utilized as the light source. The ITO electrodes
$(10 \times 15 \mathrm{~mm})$ were cleaned separately with ethanol, acetone and water for $5 \mathrm{~min}$. Next, $3 \mathrm{mg}$ catalyst powders were dispersed in a chitosan and ethanol mixed solution $(0.5 \mathrm{~mL})$ for the formation of a homogeneous suspension. Subsequently, $20 \mu \mathrm{L}$ suspensions were coated on ITO electrodes $\left(0.5 \mathrm{~cm}^{2}\right)$.

\section{Characterization}

X-ray diffraction (XRD) patterns were obtained using a Bruker D8 Advance diffractometer with $\mathrm{Cu} \mathrm{K} \alpha$ radiation. The X-ray photoelectron spectra were achieved with the help of an X-ray photoelectron spectroscope (XPS, ESCALAB 250Xi, Al Ka microfocus monochromator with variable spot size (30-400 $\mu \mathrm{m}$ and $5 \mu \mathrm{m}$ step size)). Diffuse reflection spectra (DRS) were obtained for the materials, which were verified using a UV-vis spectrophotometer, with $\mathrm{BaSO}_{4}$ as the reference. The morphologies of the samples were characterized by scanning electron microscopy (SEM) and transmission electron microscopy (TEM).

\section{Results and discussion}

\section{Choice of materials}

The phases of all synthetic materials were studied by XRD (Fig. 1A). For pure CuS, the four typical characteristic peaks around $31.78^{\circ}, 32.85^{\circ}$ and $47.94^{\circ}$ correspond to (103), (006) and (110) of CuS (JCPDS 06-0464), while the peaks at $18.98^{\circ}, 28.82^{\circ}$, $30.54^{\circ}$ and $47.30^{\circ}$ were attributed to the (110), (121), (040) and (042) lattice planes of $\mathrm{BiVO}_{4}$ (JCPDS No. 14-0688). For CuS/ $\mathrm{BiVO}_{4}$, the positions of the peaks were the same even for a variety of composites, with both $\mathrm{CuS}$ and $\mathrm{BiVO}_{4}$ peaks being clearly identifiable. More importantly, with the increase in CuS, the (110) peak became more and more prominent. All results indicate that we have successfully synthesized $\mathrm{CuS} / \mathrm{BiVO}_{4}$.

In order to conduct further evaluation of the PEC performances of CuS, $\mathrm{BiVO}_{4}$ and $\mathrm{CuS} / \mathrm{BiVO}_{4}-X$, photocurrent densities of all materials were determined under visible light irradiation in 0.1 M PBS as shown in Fig. 1B. The photocurrent densities of all the materials were of the order $\mathrm{CuS} / \mathrm{BiVO}_{4}-5 \%>\mathrm{CuS} / \mathrm{BiVO}_{4^{-}}$ $7 \%>\mathrm{CuS} / \mathrm{BiVO}_{4}-2 \%>\mathrm{BiVO}_{4}>\mathrm{CuS}$. These results show that $\mathrm{CuS}$ can efficiently improve the absorption of visible light and separate electron-hole pairs; excessive CuS will affect the capability of materials in absorbing visible light, thus reducing the PEC of the materials. ${ }^{34}$

Electrochemical impedance spectroscopy (EIS) was conducted to evaluate the electron transfer kinetics (Fig. 1C). The EIS was performed in 0.1 M PBS, which consisted of extruded semi-circular portions and linear portions. The electron transfer resistance $\left(R_{\mathrm{ct}}\right)$ was quantified based on the semicircle diameter, and it was ranked as $\mathrm{CuS}>\mathrm{BiVO}_{4}>\mathrm{CuS} / \mathrm{BiVO}_{4}-2 \%>$ $\mathrm{CuS} / \mathrm{BiVO}_{4}-7 \%>\mathrm{CuS} / \mathrm{BiVO}_{4}-5 \%$. Double-layer capacitance $\left(C_{\mathrm{dl}}\right)$, which can be obtained from cyclic voltammetry $(\mathrm{CV})$, is directly related to the electrochemical active surface area $(A)$ and the scanning rate $v$ in a linear relationship $\left(C_{\mathrm{dl}} \propto v \times A\right) .{ }^{35}$ Therefore, the values of $C_{\mathrm{dl}}$ can be used to indicate A. As shown in Fig. $\mathrm{S} 1, \uparrow$ the $C_{\mathrm{dl}}$ values were ranked CuS $\left(0.29 \mathrm{mF} \mathrm{cm}^{-2}\right)<\mathrm{BiVO}_{4}$ $\left(0.58 \mathrm{mF} \mathrm{cm}{ }^{-2}\right)<\mathrm{CuS} / \mathrm{BiVO}_{4}-2 \%\left(0.72 \mathrm{mF} \mathrm{cm}{ }^{-2}\right)<\mathrm{CuS} / \mathrm{BiVO}_{4}^{-}$ 

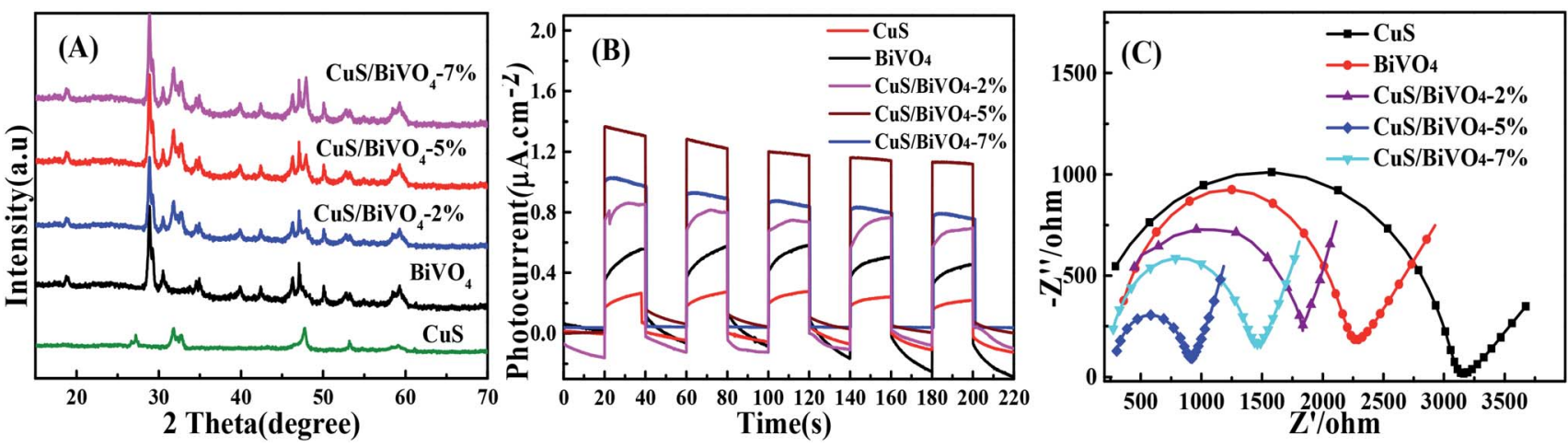

Fig. 1 XRD spectra (A), photocurrent responses (B), and EIS (C) of the CuS, BiVO 4 and CuS/BiVO $4-X$ composites in $0.1 \mathrm{M}$ PBS.

$7 \%\left(1.31 \mathrm{mF} \mathrm{cm}^{-2}\right)<\mathrm{CuS} / \mathrm{BiVO}_{4}-5 \%\left(1.49 \mathrm{mF} \mathrm{cm}^{-2}\right)$. These results are consistent with EIS. All the results indicate that $\mathrm{CuS} /$ $\mathrm{BiVO}_{4}-5 \%$ has rapid electron transfer capability, the best electrical conductivity and a large electrochemical active area, which makes it a potential active material. Based on the results shown above, $\mathrm{CuS} / \mathrm{BiVO}_{4}-5 \%$ was selected for further investigation.

\section{Physical characterization}

SEM, TEM and HRTEM analysis clearly defined the morphology of the pure $\mathrm{BiVO}_{4}$ and $\mathrm{CuS} / \mathrm{BiVO}_{4}-5 \%$ composite. The results are shown in Fig. 2. Pure $\mathrm{BiVO}_{4}$ particles had the shape of a peanut with a smooth surface (Fig. $2 \mathrm{~A}$ and $\mathrm{C}$ ). As compared to the pure $\mathrm{BiVO}_{4}$, the surface of $\mathrm{CuS} / \mathrm{BiVO}_{4}-5 \%$ is rough (Fig. $2 \mathrm{~B}$ and D). The $\mathrm{CuS} / \mathrm{BiVO}_{4}-5 \%$ composite structure was further verified by HRTEM analysis. As shown in Fig. 2E, the lattice fringes of 0.309 and $0.323 \mathrm{~nm}$ correspond to the (121) planes of $\mathrm{BiVO}_{4}$ and the (101) planes of CuS, respectively, which suggests the coexistence of $\mathrm{BiVO}_{4}$ and $\mathrm{CuS}$ in the composites. Fig. $2 \mathrm{~F}$ shows the STEMEDX mapping images of $\mathrm{CuS} / \mathrm{BiVO}_{4}-5 \%$, which indicates that the $\mathrm{Bi}, \mathrm{V}, \mathrm{O}, \mathrm{Cu}$ and $\mathrm{S}$ elements in the composite surface are uniformly distributed. The results further show that $\mathrm{CuS} / \mathrm{BiVO}_{4}{ }^{-}$ $5 \%$ is composed of $\mathrm{BiVO}_{4}$ and CuS, which conforms to the XPS analysis.

We studied the absorption properties of $\mathrm{BiVO}_{4}$, $\mathrm{CuS}$ and $\mathrm{CuS} /$ $\mathrm{BiVO}_{4}-5 \%$ by UV-vis DRS as shown in Fig. 3A. The pure CuS exhibited strong ultraviolet and visible absorption, while the pure $\mathrm{BiVO}_{4}$ showed the absorption edge at approximately $550 \mathrm{~nm}$. Furthermore, the visible absorption ability of $\mathrm{CuS} /$ $\mathrm{BiVO}_{4}$ was significantly higher as compared to $\mathrm{BiVO}_{4}$. All these can be attributed to the inner absorption of CuS. Based on the fundamental idea of electronegativity, ${ }^{36}$ the band gap energy was calculated using eqn (1):

$$
\alpha h \nu=A\left(\nu h-E_{\mathrm{g}}\right)^{n / 2}
$$

where $n$ is the optical transition type, $\mathrm{BiVO}_{4}$ is a not direct semiconductor and the value of $n$ is 4 . A is a constant, $\nu$ represents the incident light frequency, $h$ is Planck's constant, and $\alpha$ is the absorption coefficient. Fig. S2 $\uparrow$ suggests that the $E_{\mathrm{g}}$ energy gap of $\mathrm{BiVO}_{4}$ is $2.52 \mathrm{eV}$. CuS refers to a direct semiconductor, so $n$ is $1 .^{32}$ Accordingly, the band gap of CuS was nearly $2.26 \mathrm{eV}$. Next, the ability of synthetic materials for separating holes and electrons was studied based on PL spectra. Fig. 3B suggests that $\mathrm{CuS} / \mathrm{BiVO}_{4}-5 \%$ has the lowest intensity as compared with CuS and $\mathrm{BiVO}_{4}$, suggesting that $\mathrm{CuS} / \mathrm{BiVO}_{4}-5 \%$ has a low electron recombination rate. ${ }^{16}$ According to the discussion above, $\mathrm{CuS} / \mathrm{BiVO}_{4}-5 \%$ displayed terrific PEC performance.

\section{Photoelectrochemical sensor}

Fig. $4 \mathrm{~A}$ and $\mathrm{B}$ suggests the photocurrent performance of $\mathrm{CuS}$, $\mathrm{BiVO}_{4}$ and $\mathrm{CuS} / \mathrm{BiVO}_{4}-5 \%$ at $0 \mathrm{~V} v$ s. SCE with the addition of 1 $\mu \mathrm{M}$ DA and BPA under visible light excitation in 0.1 M PBS. The photocurrent of all synthetic materials increased with the addition of DA and BPA. Meanwhile, the photocurrent of CuS/ $\mathrm{BiVO}_{4}-5 \%$ was larger than that of $\mathrm{BiVO}_{4}$, since the p-n heterostructure improved the PEC efficiency for DA and BPA to a large extent.

To further evaluate the PEC performance of $\mathrm{CuS} / \mathrm{BiVO}_{4}-5 \%$ for DA and BPA, the photocurrent change was ascertained at many different concentrations of DA and BPA. By the respective addition of DA, the photocurrent response increased significantly as shown in Fig. 4C. A linear relationship was found between the concentration of DA and photocurrent (Fig. 4D), and it displays two linear associations based on the sensor of $\mathrm{CuS} / \mathrm{BiVO}_{4}-5 \%$ for DA. From $0.01-10 \mu \mathrm{M}$, the linear regressing equation is $\Delta I=0.2807+0.5622 c\left(R^{2}=0.9918\right)$, ranging from 10 to $120 \mu \mathrm{M}$; the linear association is $\Delta I=5.1966+0.0712 c\left(R^{2}=\right.$ $0.9942)$. The detection limit of the sensor is $3.4 \mathrm{nM}(\mathrm{S} / \mathrm{N}=3)$.

Experiments for BPA detection were performed in PBS (Fig. 4E and F). On increasing the BPA concentration in PBS, the photocurrent increased and the as-prepared $\mathrm{CuS} / \mathrm{BiVO}_{4}-5 \%$ photoelectrode detected BPA with a linear range from $0.01 \mu \mathrm{M}$ to $90 \mu \mathrm{M}$. The linear regressing equation is $\Delta I=0.7052+$ $0.0574 c\left(R^{2}=0.9911\right)$ with a detection limit $(\mathrm{S} / \mathrm{N}=3)$ of $7 \mathrm{nM}$. In Table 1 a comparison is made of $\mathrm{CuS} / \mathrm{BiVO}_{4}-5 \%$ with other DA and BPA sensors in the literature. It is undeniable that the CuS/ $\mathrm{BiVO}_{4}-5 \%$ sensor outperforms the other DA and BPA sensors in several fields.

By monitoring the photocurrent of the repeated photoexcitation over $600 \mathrm{~s}$, the $\mathrm{CuS} / \mathrm{BiVO}_{4}-5 \%$ stability was also checked 

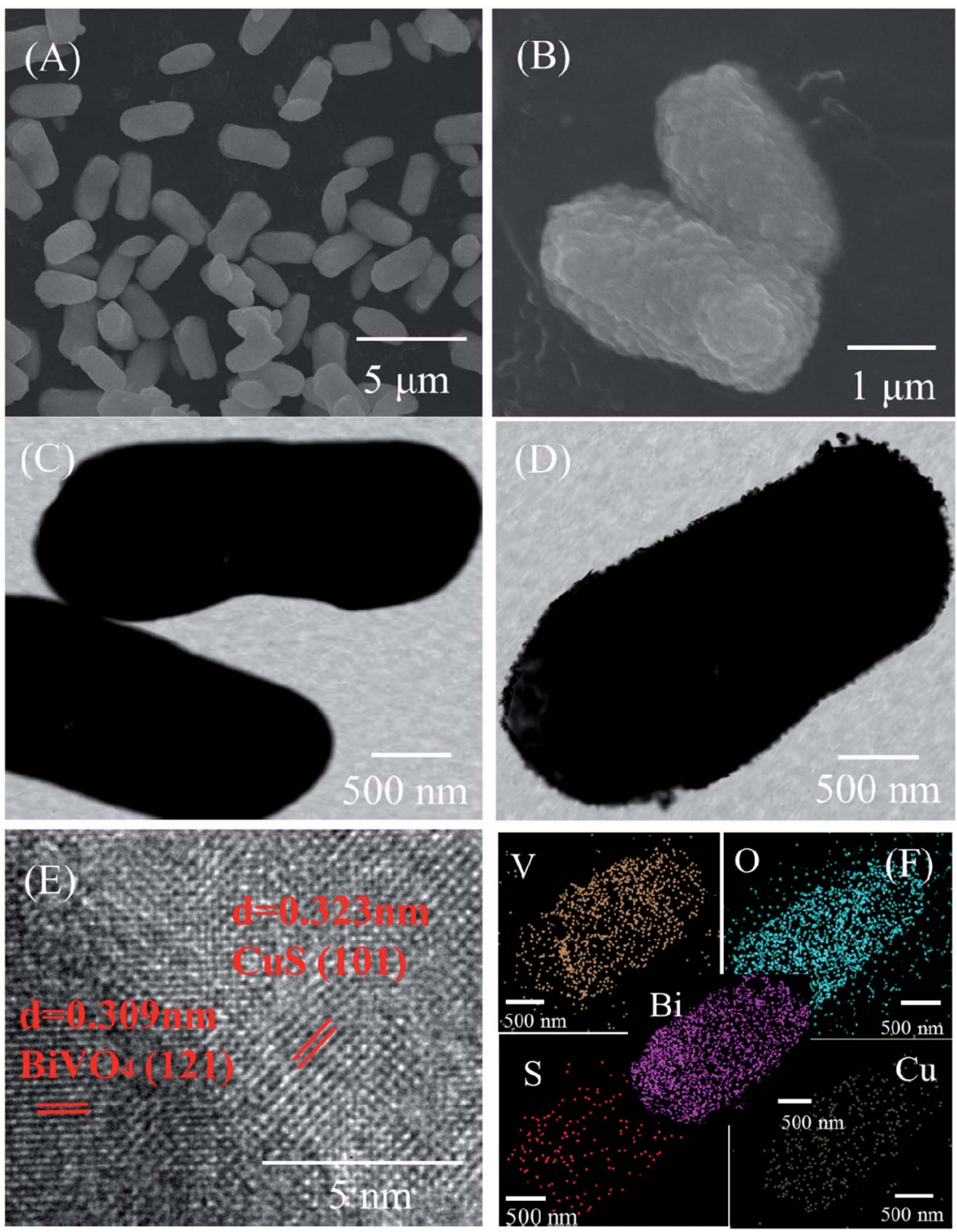

Fig. 2 SEM images of $\mathrm{BiVO}_{4}(\mathrm{~A})$ and CuS/BiVO $4-5 \%$ (B). TEM images of $\mathrm{BiVO}_{4}$ (C) and CuS/BiVO $-5 \%$ (D). (E) HR-TEM images of CuS/BiVO $-5 \%$. (F) STEM-EDX mapping images of $\mathrm{CuS} / \mathrm{BiVO}_{4}-5 \%$

(Fig. S3†). The response photocurrent of $\mathrm{CuS} / \mathrm{BiVO}_{4}-5 \%$ remained at $95.3 \%$ and $95.8 \%$ of its initial value towards $1 \mu \mathrm{M}$ DA and $1 \mu \mathrm{M}$ BPA within 18 days (Fig. 6A and C). XPS of CuS/
$\mathrm{BiVO}_{4}-5 \%$ before the stability test was also evaluated, as shown in Fig. 5A. For Bi 4f, O 1s, V 2p, Cu 2p and $\mathrm{S} 2 \mathrm{~s}$, the high resolution is shown in Fig. 5B-F. Fig. 5B shows two core peaks of the
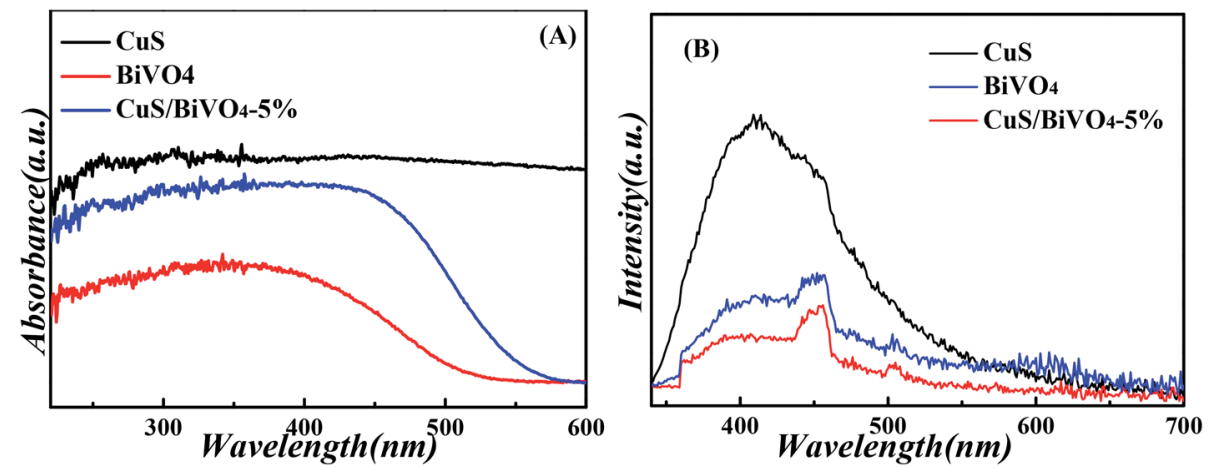

Fig. 3 UV-vis diffuse reflectance spectra (A), and PL spectra (B) of the CuS, $\mathrm{BiVO}_{4}$ and $\mathrm{CuS} / \mathrm{BiVO}_{4}-5 \%$ composites. 

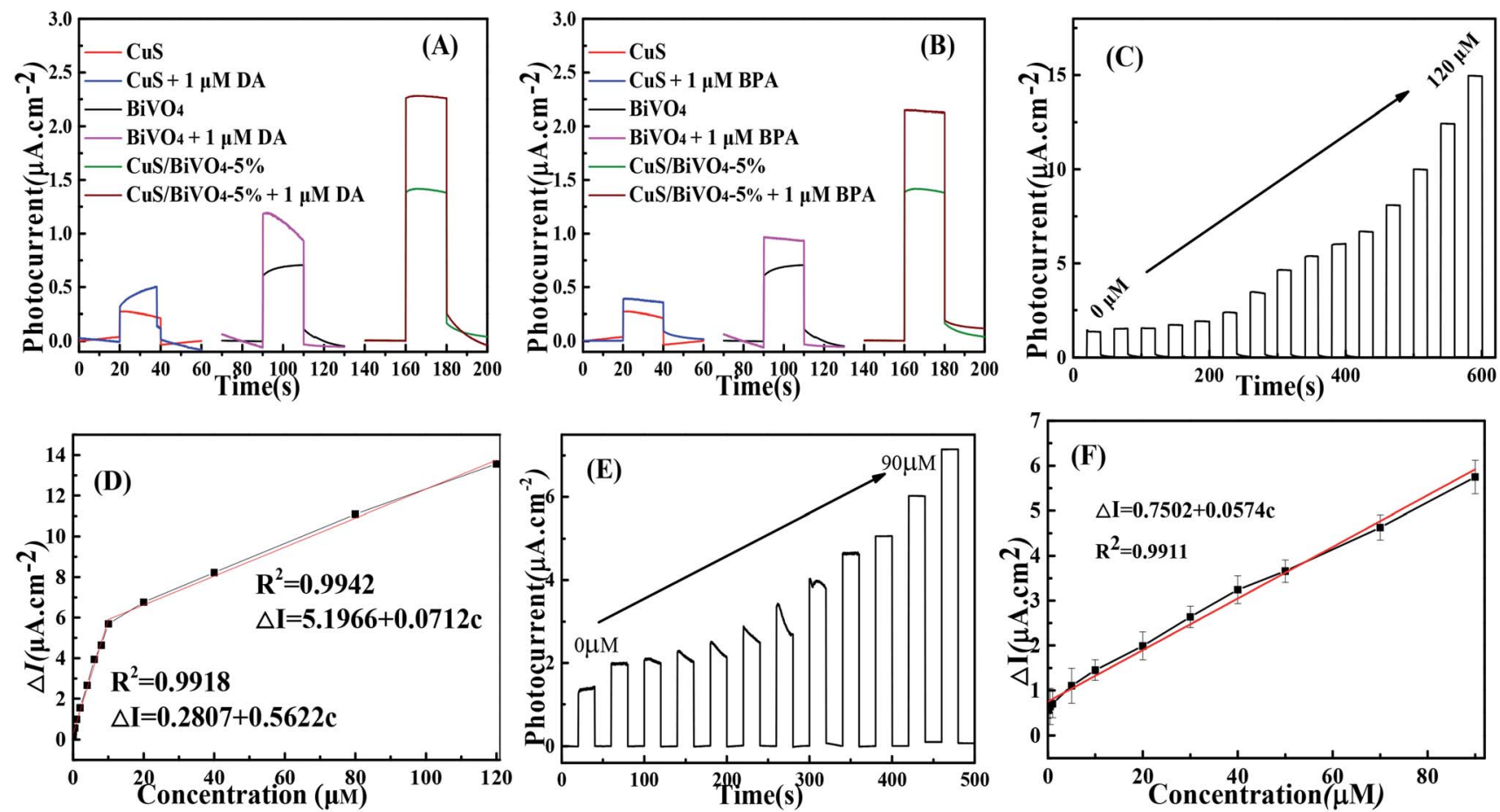

Fig. 4 Photocurrent responses of the CuS, $\mathrm{BiVO}_{4}$ and CuS/BiVO $4-5 \%$ composites with and without $1 \mu \mathrm{M}$ DA (A) and $1 \mu \mathrm{M}$ BPA (B). (C) Photocurrent responses of $\mathrm{CuS} / \mathrm{BiVO}_{4}-5 \%$ toward DA with increasing concentrations of DA. (D) The relevant calibration plots of the DA concentration. (E) Photocurrent responses of $\mathrm{CuS} / \mathrm{BiVO}_{4}-5 \%$ toward BPA with increasing concentrations of BPA. (F) The relevant calibration plots of the BPA concentration in $0.1 \mathrm{M}$ PBS at $0 \mathrm{~V}$ vs. SCE as excited by visible light.

Bi 4 f XPS spectra situated at $158.8 \mathrm{eV}$ and $164.2 \mathrm{eV}$. The peaks at $164.2 \mathrm{eV}$ and $158.8 \mathrm{eV}$ are attributed to $\mathrm{Bi} 4 \mathrm{f}_{5 / 2}$ and $\mathrm{Bi} 4 \mathrm{f}_{7 / 2}$ in normal $\mathrm{Bi}^{3+} \cdot{ }^{37}$ The two $2 \mathrm{p}_{3 / 2}(516.5 \mathrm{eV})$ and $2 \mathrm{p}_{1 / 2}(523.9 \mathrm{eV})$ peaks of biological iodine correspond to $\mathrm{V}^{5+}$ (Fig. 5C). ${ }^{38}$ The O $1 \mathrm{~s}$ peak is shown in Fig. 5D, and the $\mathrm{O} 1 \mathrm{~s}$ peak at $530.46 \mathrm{eV}$ is due to the lattice oxygen. ${ }^{39} \mathrm{Cu} 3 \mathrm{p}_{1 / 2}$ at $951.8 \mathrm{eV}$ and $\mathrm{Mo} 3 \mathrm{p}_{3 / 2}$ at $931.9 \mathrm{eV}$ are matched to $\mathrm{Cu}^{2+}$ in Fig. $5 \mathrm{E} .^{40}$ In Fig. $2 \mathrm{~F}$, the $2 \mathrm{~s}$ peak at around $226.1 \mathrm{eV}$ was attributed to $\mathrm{S} 2 \mathrm{~s}$, which strongly proved how $\mathrm{CuS}^{41}$ was formed. Fig. S4 $\uparrow$ shows that the XRD and XPS of $\mathrm{CuS} / \mathrm{BiVO}_{4}-5 \%$ after the stability test. All the results show that $\mathrm{CuS} / \mathrm{BiVO}_{4}-5 \%$ has the best stability. The reproducibility of CuS/ BiVO $_{4}-5 \%$ was tested by detecting $1 \mu \mathrm{M}$ DA and BPA using 5 parallel electrodes (Fig. 6B and D), and the photocurrent did not exhibit any significant variation, indicating its good reproducibility.

The selectivity of the PEC sensor based on $\mathrm{CuS} / \mathrm{BiVO}_{4}-5 \%$ towards DA and BPA is shown in Fig. S5; $\uparrow$ the photocurrent responses of interferences can be ignored, implying that $\mathrm{CuS} /$ BiVO $_{4}-5 \%$ can selectively and effectively detect DA and BPA. To verify the practical reliability of the DA and BPA sensor that has been prepared, we used lake water containing BPA, and human blood serum containing DA as convincing samples. As shown in Table 2, for DA, the RSD values are less than $4.21 \%$, and the recoveries are $99.80-101.0 \%$. For BPA, the RSD values are less than $3.19 \%$, and the recoveries are $98.00-100.12 \%$. According to

Table 1 Comparison of different methods for detecting DA and BPA

\begin{tabular}{|c|c|c|c|c|c|}
\hline Method & Materials & Analyst & Linear range $(\mu \mathrm{M})$ & LOD & Ref. \\
\hline Fluorescent & $\mathrm{MoS}_{2}$ & DA & $0.1-100$ & $10 \mathrm{nM}$ & 42 \\
\hline Electrochemical & $\mathrm{CuO} / \mathrm{CN}$ & DA & $0.2-78.7$ & $0.06 \mu \mathrm{M}$ & 4 \\
\hline Electrochemical & RGO-ZnO & DA & $1-70$ & $0.33 \mu \mathrm{M}$ & 43 \\
\hline PEC & SnSe NSs & DA & $0.01-10$ & $3 \mathrm{nM}$ & 7 \\
\hline PEC & $\mathrm{WO}_{3}$ & DA & $53-80,85-155$ & $0.3 \mu \mathrm{M}$ & 44 \\
\hline PEC & $\mathrm{CuS} / \mathrm{BiVO}_{4}$ & DA & $\begin{array}{l}0.01-10 \\
10-120\end{array}$ & $3.4 \mathrm{nM}$ & This work \\
\hline Fluorescence polarization immunoassay & 4,4-Bis(4-hydroxyphenyl)valeric acid & BPA & $0.087-3.5$ & $8.7 \mathrm{nM}$ & 45 \\
\hline PEC & $\mathrm{TiO}_{2} / \mathrm{Au}$ NTAs & BPA & $0.1-28.9$ & $0.047 \mu \mathrm{M}$ & 9 \\
\hline PEC & $\mathrm{ZnPc} / \mathrm{TiO}_{2} \mathrm{NRs}$ & BPA & $0.047-52.1$ & $8.6 \mathrm{nM}$ & 46 \\
\hline PEC & $\mathrm{CuS} / \mathrm{BiVO}_{4}$ & BPA & $0.01-90$ & $7 \mathrm{nM}$ & This work \\
\hline
\end{tabular}



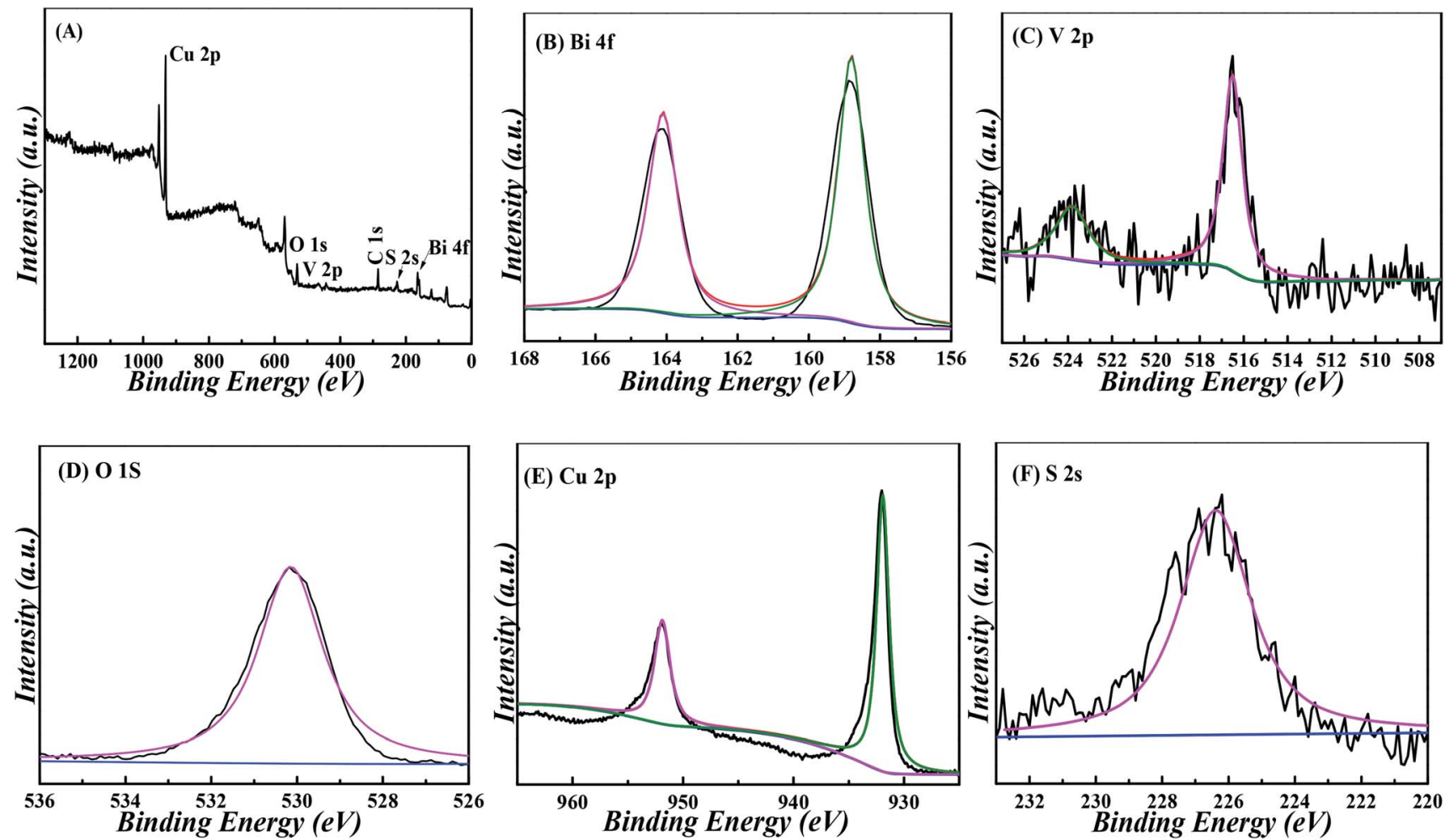

Fig. 5 XPS spectra of CuS/BiVO $4-5 \%$ composites: (A) survey, (B) $\mathrm{Bi} 4 \mathrm{f},(\mathrm{C}) \vee 2 \mathrm{p}$, (D) O 1s, (E) Cu $2 \mathrm{p}$ and (F) S 2s.
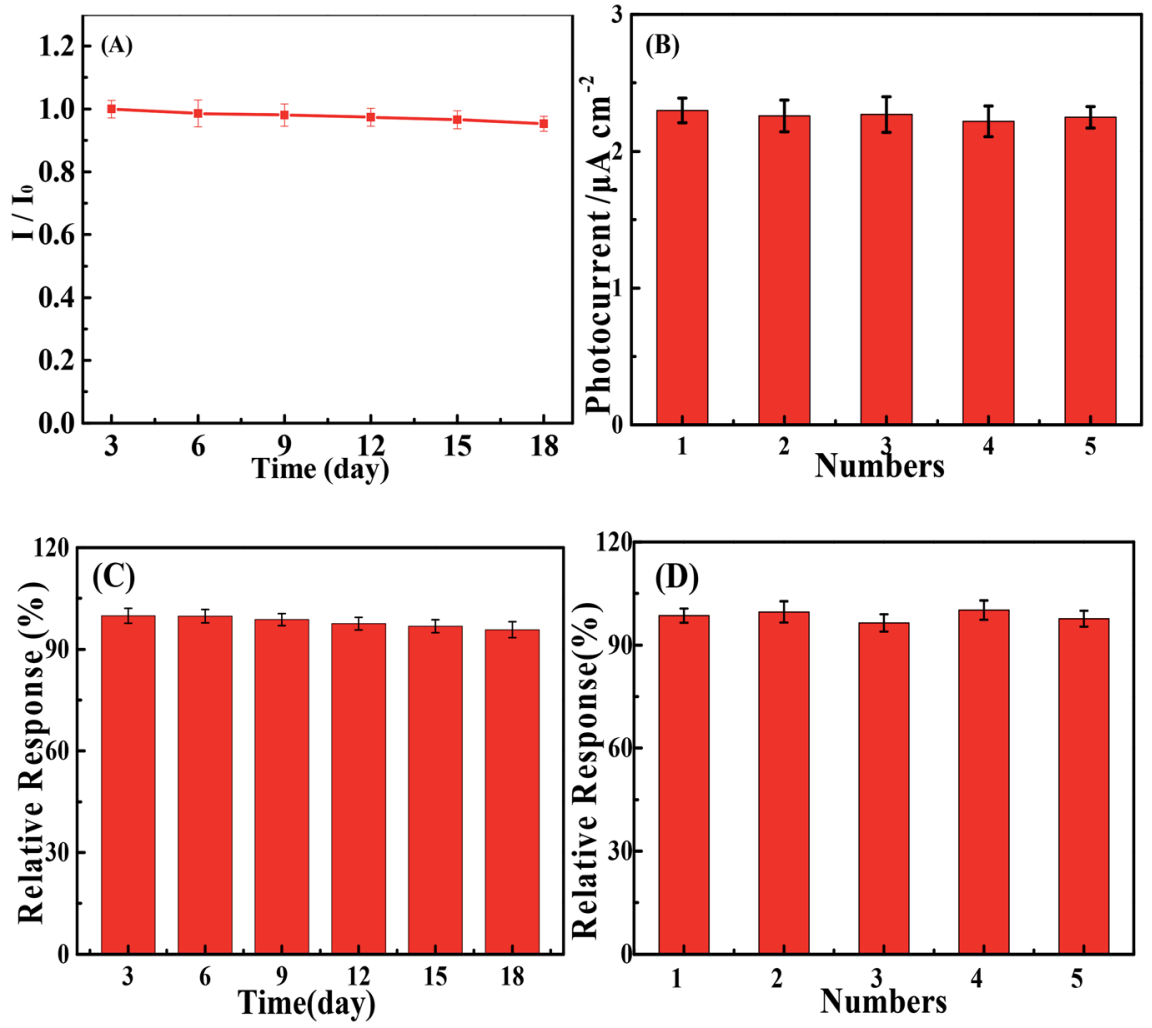

Fig. 6 Stability and reproducibility tests of the PEC sensor based on CuS/BiVO $4-5 \%$ towards DA (A and B) and BPA (C and D). 
Table 2 PEC detection of DA and BPA in real samples

\begin{tabular}{|c|c|c|c|c|}
\hline Real samples & Added $(\mu \mathrm{M})$ & Found $(\mu \mathrm{M})$ & Recovery (\%) & $\operatorname{RSD}(\%)$ \\
\hline \multirow{4}{*}{$\begin{array}{l}\text { Human blood serum } \\
\text { (DA) }\end{array}$} & 1.00 & 1.01 & 101.00 & 1.31 \\
\hline & 5.00 & 4.95 & 99.90 & 2.24 \\
\hline & 50.00 & 49.92 & 99.84 & 3.52 \\
\hline & 100.00 & 99.96 & 99.96 & 4.21 \\
\hline \multirow[t]{3}{*}{ Lake water (BPA) } & 1.00 & 0.98 & 98.00 & 1.01 \\
\hline & 40.00 & 40.05 & 100.12 & 2.71 \\
\hline & 80.00 & 80.09 & 100.11 & 3.19 \\
\hline
\end{tabular}

the mentioned results, the sensor based on $\mathrm{CuS} / \mathrm{BiVO}_{4}-5 \%$ is reliable for the detection of DA and BPA in actual samples.

\section{Proposed mechanism of PEC}

To explore the mechanism of PEC sensors based on $\mathrm{CuS} / \mathrm{BiVO}_{4}$, the valence band energy $\left(E_{\mathrm{VB}}\right)$ and the conduction band energy $\left(E_{\mathrm{CB}}\right)$ of $\mathrm{BiVO}_{4}$ and $\mathrm{CuS}$ were investigated with the aid of the following equation: ${ }^{47}$

$$
\begin{gathered}
E_{\mathrm{VB}}=X-E_{\mathrm{e}}+0.5 E_{\mathrm{g}} \\
E_{\mathrm{CB}}=E_{\mathrm{VB}}-E_{\mathrm{g}}
\end{gathered}
$$

The value of $E_{\mathrm{e}}$ was almost $4.5 \mathrm{eV}$, indicating the energy of free the electrons at the scale of hydrogen. $X$ represents the semiconductor electronegativity, and $X$ was $6.04 \mathrm{eV}$ and $5.29 \mathrm{eV}$ for $\mathrm{BiVO}_{4}$ and CuS, respectively. The VB edges of $\mathrm{BiVO}_{4}$ and $\mathrm{CuS}$ were $+2.8 \mathrm{eV}$ and $+1.92 \mathrm{eV}$, respectively. Besides, we determined the $\mathrm{CB}$ edge potentials of $\mathrm{BiVO}_{4}$ and $\mathrm{CuS}$ as $+0.28 \mathrm{eV}$ and $-0.34 \mathrm{eV}$, respectively. As shown in Fig. 7, the migrating process of photogenerated electrons occurs from the $\mathrm{CB}$ of $\mathrm{CuS}$ to the $\mathrm{CB}$ of $\mathrm{BiVO}_{4}$ and the holes are transferred from the $\mathrm{VB}$ of $\mathrm{BiVO}_{4}$ to the VB of CuS due to the dynamic principle, which could help divide the photogenerated electron-hole pairs to effectively utilize the oxidization of holes. By the same token, the holes will be utilized to oxidize DA and BPA.

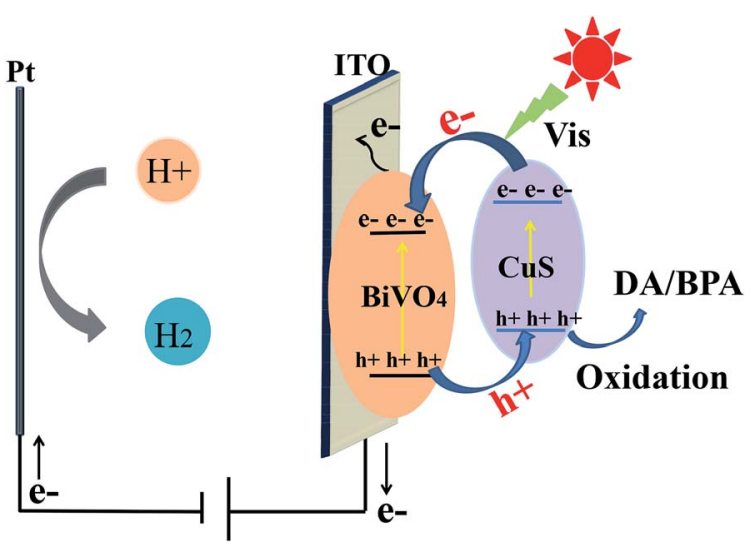

Fig. 7 PEC mechanism of CuS/BiVO ${ }_{4}$ for the detection of DA and BPA.

\section{Conclusion}

In summary, we have designed a $\mathrm{CuS} / \mathrm{BiVO}_{4}$ composite via a two-step hydrothermal method. $\mathrm{CuS} / \mathrm{BiVO}_{4}-5 \%$ exhibited superior PEC properties for DA and BPA as compared with pure $\mathrm{BiVO}_{4}, \mathrm{CuS}$ and $\mathrm{CuS} / \mathrm{BiVO}_{4}-X$. The CuS content had an impact on the PEC efficiency of $\mathrm{CuS} / \mathrm{BiVO}_{4}$. The PEC efficiency and stability of $\mathrm{CuS} / \mathrm{BiVO}_{4}$ can be attributed to the appropriate CuS content as well as the influential electron-hole pair separation. The study indicates that the sensor based on $\mathrm{CuS} / \mathrm{BiVO}_{4}-5 \%$ is sure to possess great application prospects for DA and BPA PEC detection.

\section{Conflicts of interest}

There are no conflicts to declare.

\section{Acknowledgements}

This work was supported by the Natural Science Foundation of Henan Province (Grant No.: 162300410290) and the National Key Research and Development Program of China (Grant No.: 2016YFC1303204).

\section{References}

1 T. D. P. Allsop, R. Neal, C. Wang, D. A. Nagel, A. V. Hine, P. Culverhouse, J. D. A. Castañón, D. J. Webb, S. Scarano and M. Minunni, Biosens. Bioelectron., 2019, 135, 102-110.

2 M. K. Li, L. Y. Hu, C. G. Niu, D. W. Huang and G. M. Zeng, Sens. Actuators, B, 2018, 266, 805-811.

3 A. S. Alnaimat, M. C. B. Alonso and P. B. Barrera, Microchem. J., 2019, 147, 598-604.

4 S. Reddy, B. E. K. Swamy and H. Jayadevappa, Electrochim. Acta, 2012, 61, 78-86.

5 M. Annalakshmi, P. Balasubramanian, S. M. Chen, T. W. Chen and P. H. Lin, Inorg. Chem. Front., 2019, 6, 2024-2034.

6 L. A. Goulart, S. A. Alves and L. H. Mascaro, Electroanal. Chem., 2019, 839, 123-133.

7 X. Hun, S. S. Wang, S. Y. Mei, H. Q. Qin, H. Zhang and H. L. Luo, Microchim. Acta, 2017, 184, 3333-3338. 
8 Y. H. Song, J. J. Han, L. J. Xu, L. F. Miao, C. W. Peng and L. Wang, Sens. Actuators, B, 2019, 298, 126949.

9 L. S. Hu, C. C. Fong, X. M. Zhang, L. L. Chan, P. K. S. Lam, P. K. Chu, K. Y. Wong and M. S. Yang, Environ. Sci. Technol., 2016, 50, 4430-4438.

10 A. M. Ahmed, F. Mohamed, A. M. Ashraf, M. Shaban, A. A. P. Khan and A. M. Asiri, Chemosphere, 2019, 124554.

11 Y. Liu, Y. S. Chang, Y. J. Hsu, B. J. Hwang and C. H. Hsueh, Fabrication of $\mathrm{WO}_{3}$ photoanode decorated with $\mathrm{Au}$ nanoplates and its enhanced photoelectrochemical properties, Electrochim. Acta, 2019, 134674.

12 X. L. Tu, M. Li, Y. J. Su, G. L. Yin, J. Lu and D. N. He, Selftemplated growth of CuInS2 nanosheet arrays for photoelectrochemical water splitting, J. Alloys Compd., 2019, 151794.

13 L. F. Wang, W. Q. Zhu, W. B. Lu, L. N. Shi, R. Wang, R. X. Pang, Y. Y. Cao, F. Wang and X. H. Xu, One-step electrodeposition of AuNi nanodendrite arrays as photoelectrochemical biosensors for glucose and hydrogen peroxide detection, Biosens. Bioelectron., 2019, 111577.

14 F. G. Cai, X. Chen, L. X. Qiu, L. L. Jiang, S. D. Ma, Q. Y. Zhang and Y. Zhao, Controlled hydrothermal synthesis and photoelectrochemical properties of $\mathrm{Bi}_{2} \mathrm{~S}_{3} / \mathrm{TiO}_{2}$ nanotube arrays heterostructure, J. Alloys Compd., 2019, 151770.

15 H. L. Tong, Y. Jiang, Q. Zhang, W. C. Jiang, K. L. Wang, X. X. Luo, Z. Lin and L. X. Xia, Boosting Photoelectrochemical Water Oxidation with Cobalt Phosphide Nanosheets on Porous $\mathrm{BiVO}_{4}$, ACS Sustainable Chem. Eng., 2019, 7, 769-778.

16 W. J. He, Y. J. Sun, G. M. Jiang, Y. H. Li, X. M. Zhang, Y. X. Zhang, Y. Zhou and F. Dong, Defective $\mathrm{Bi}_{4} \mathrm{MoO}_{9} / \mathrm{Bi}$ metal core/shell heterostructure: Enhanced visible light photocatalysis and reaction mechanism, Appl. Catal., B, 2018, 239, 619-627.

17 F. Rong, Q. Y. Wang, Q. F. Lu, L. B. Yao and M. Z. Wei, Rational Fabrication of Hierarchical Z-Scheme $\mathrm{WO}_{3} /$ $\mathrm{Bi}_{2} \mathrm{WO}_{6}$ Nanotubes for Superior Photoelectrocatalytic Reaction, ChemistrySelect, 2019, 4, 2676-2684.

18 J. Qian, Z. T. Yang, C. Q. Wang, K. Wang, Q. Liu, D. Jiang, Y. T. Yan and K. Wang, One-pot synthesis of BiPO4 functionalized reduced graphene oxide with enhanced photoelectrochemical performance for selective and sensitive detection of chlorpyrifos, J. Mater. Chem. A, 2015, 3, 13671-13678.

19 J. L. Lv, J. F. Zhang, J. Liu, Z. Li, K. Dai and C. H. Liang, Bi SPR-promoted Z-scheme $\mathrm{Bi}_{2} \mathrm{MoO}_{6} / \mathrm{CdS}$-diethylenetriamine composite with effectively enhanced visible light photocatalytic hydrogen evolution activity and stability, ACS Sustainable Chem. Eng., 2017, 6, 696-706.

20 F. Yang, X. M. Zhu, J. Z. Fang, D. D. Chen, W. H. Feng and Z. Q. Fang, One step solvothermal synthesis of $\mathrm{Bi} / \mathrm{BiPO}_{4} /$ $\mathrm{Bi}_{2} \mathrm{WO}_{6}$ heterostructure with oxygen vacancies for enhanced photocatalytic performance, Ceram. Int., 2018, 44, 6918-6925.

21 H. L. Li, Y. J. Chen, W. Zhou, H. Y. Jiang, H. Liu, X. Chen and T. G. Hui, $\mathrm{WO}_{3} / \mathrm{BiVO}_{4} / \mathrm{BiOCl}$ porous nanosheet composites from a biomass template for photocatalytic organic pollutant degradation, J. Alloys Compd., 2019, 802, 76-85.

22 H. D. She, M. Jiang, P. F. Yue, J. W. Huang, L. Wang, J. Z. Lie, G. Q. Zhu and G. Z. Wang, Metal $\left(\mathrm{Ni}^{2+} / \mathrm{Co}^{2+}\right)$ sulfides modified $\mathrm{BiVO}_{4}$ for effective improvement in photoelectrochemical water splitting, J. Colloid Interface Sci., 2019, 549, 80-88.

23 L. X. Sun, J. H. Sun, N. Han, D. K. Liao, S. L. Bai, X. J. Yang, R. X. Luo, D. Q. Li and A. F. Chen, rGO decorated W doped $\mathrm{BiVO}_{4}$ novel material for sensing detection of trimethylamine, Sens. Actuators, B, 2019, 298, 126749.

24 K. J. Li, J. Han, Y. Yang, T. Wang, Y. Q. Feng, S. Ajmal, Y. Y. Liu, Y. Deng, M. A. Tahir and L. W. Zhang, Simultaneous $\mathrm{SO}_{2}$ removal and $\mathrm{CO}_{2}$ reduction in a nano$\mathrm{BiVO}_{4} \mid \mathrm{Cu}-\mathrm{In}$ nanoalloy photoelectrochemical cell, Chem. Eng. J., 2019, 355, 11-21.

$25 \mathrm{~F}$. Li, W. Zhao and D. Y. C. Leung, Enhanced photoelectrocatalytic hydrogen production via $\mathrm{Bi} / \mathrm{BiVO}_{4}$ photoanode under visible light irradiation, Appl. Catal., B, 2019, 258, 117954.

26 H. C. He, Y. Zhou, G. L. Ke, X. H. Zhong, M. J. Yang, L. Bian, K. L. Lv and F. Q. Dong, Improved Surface Charge Transfer in $\mathrm{MoO}_{3} / \mathrm{BiVO}_{4}$ Heterojunction Film for Photoelectrochemical Water Oxidation, Electrochim. Acta, 2017, 257, 181-191.

27 T. Kosmala, D. Mosconi, G. Giallongo, G. A. Rizzi and G. Granozzi, Highly Efficient $\mathrm{MoS}_{2} / \mathrm{Ag}_{2} \mathrm{~S} / \mathrm{Ag}$ Photoelectrocatalyst Obtained from a Recycled DVD Surface, ACS Sustainable Chem. Eng., 2018, 66, 7818-7825.

28 C. E. Chieh, C. Jian, C. Wan, Z. J. Huei, H. J. Hsien, L. K. Chan, H. B. Cheng and H. Y. Sheng, Microwaveassisted synthesis of $\mathrm{TiO}_{2} / \mathrm{WS}_{2}$ heterojunctions with enhanced photocatalytic activity, J. Taiwan Inst. Chem. Eng., 2018, 91, 489-498.

29 H. Wang, H. L. Ye, B. H. Zhang, F. Q. Zhao and B. Z. Zeng, Electrostatic Interaction Mechanism Based Synthesis of ZScheme BiOI-CdS Photocatalyst for Selective and Sensitive Detection of $\mathrm{Cu}^{2+}$, J. Mater. Chem. A, 2017, 5, 10599.

30 Y. F. Tang, Y. Chai, X. Q. Liu, L. L. Li, L. W. Yang, P. P. Liu, Y. M. Zhou, H. X. Ju and Y. Z. Cheng, A photoelectrochemical aptasensor constructed with core-shell CuS-TiO2 heterostructure for detection of microcystin-LR, Biosens. Bioelectron., 2018, 117, 224-231.

31 S. F. Jia, X. Y. Li, B. P. Zhang, J. Yang, S. W. Zhang, S. Li and Z. T. Zhang, $\mathrm{TiO}_{2} / \mathrm{CuS}$ heterostructure nanowire array photoanodes toward water oxidation: The role of CuS, Appl. Surf. Sci., 2019, 463, 829-837.

32 C. Lai, M. M. Zhang, B. S. Li, D. L. Huang, G. M. Zeng, L. Qin, X. G. Liu, H. Yi, M. Cheng, L. Li, Z. Chen and L. Chen, Fabrication of $\mathrm{CuS} / \mathrm{BiVO}_{4}$ (040) binary heterojunction photocatalysts with enhanced photocatalytic activity for Ciprofloxacin degradation and mechanism insight, Chem. Eng. J., 2019, 358, 891-902.

33 J. Cao, B. Y. Xu, H. L. Lin and S. F. Chen, Highly improved visible light photocatalytic activity of $\mathrm{BiPO}_{4}$ through fabricating a novel $\mathrm{p}-\mathrm{n}$ heterojunction $\mathrm{BiOI} / \mathrm{BiPO}_{4}$ nanocomposite, Chem. Eng. J., 2013, 228, 482-488. 
34 P. C. Yan, D. S. Jiang, H. N. Li, M. Cheng, L. Xu, J. C. Qian, J. Bao, J. X. Xia and H. M. Li, Exploitation of a photoelectrochemical sensing platform for catechol quantitative determination using $\mathrm{BiPO}_{4}$ nanocrystals/BiOI heterojunction, Anal. Chim. Acta, 2018, 1042, 11-19.

35 J. D. Benck, Z. Chen, L. Y. Kuritzky, A. J. Forman and T. F. Jaramillo, Amorphous Molybdenum Sulfide Catalysts for Electrochemical Hydrogen Production: Insights into the Origin of Their Catalytic Activity, ACS Catal., 2012, 2, 1916-1923.

36 W. S. Kuo and P. H. Ho, Solar photocatalytic decolorization of dyes in solution with TiO2 film, Dyes Pigm., 2006, 71, 212217.

37 X. Zhang, X. B. Wang, L. M. Wang, W. K. Wang, L. L. Long, W. W. Li and H. Q. Yu, Synthesis of a highly efficient BiOCl single-crystal nanodisk photocatalyst with exposing \{001\} Facets, ACS Appl. Mater. Interfaces, 2014, 6, 7766-7772.

38 Z. H. Wei, Y. F. Wang, Y. Y. Li, L. Zhang, H. C. Yao and Z. J. Li, Enhanced photocatalytic $\mathrm{CO}_{2}$ reduction activity of Z-scheme CdS/BiVO 4 nanocomposite with thinner $\mathrm{BiVO}_{4}$ nanosheets, J. CO2 Util., 2018, 28, 15-25.

39 X. L. Luo, Z. Y. Chen, S. Y. Yang and Y. H. Xu, Two-step hydrothermal synthesis of peanut-shaped molybdenum diselenide/bismuth vanadate $\left(\mathrm{MoSe}_{2} / \mathrm{BiVO}_{4}\right)$ with enhanced visible-light photocatalytic activity for the degradation of glyphosate, J. Colloid Interface Sci., 2018, 532, 456-463.

40 Y. P. Bhoi and B. G. Mishra, Photocatalytic degradation of alachlor using type-II $\mathrm{CuS} / \mathrm{BiFeO}_{3}$ heterojunctions as novel photocatalyst under visible light irradiation, Chem. Eng. J., 2018, 344, 391-401.
41 Y. P. Bhoi, C. Behera, D. Majhi, S. M. Equeenuddin and B. G. Mishra, Visible light-assisted photocatalytic mineralization of diuron pesticide using novel type II CuS/ $\mathrm{Bi}_{2} \mathrm{~W}_{2} \mathrm{O}_{9}$ heterojunctions with a hierarchical microspherical structure, New J. Chem., 2018, 42, 281-292.

42 X. N. Liu, W. T. Zhang, L. J. Huang, N. Hu, W. Liu, Y. N. Liu, S. H. Li, C. Y. Yang, Y. R. Suo and J. L. Wang, Fluorometric determination of dopamine by using molybdenum disulfide quantum dots, Microchim. Acta, 2018, 185, 234.

43 X. Zhang, Y. Zhang and L. Ma, One-pot facile fabrication of graphene-zinc oxide composite and its enhanced sensitivity for simultaneous electrochemical detection of ascorbic acid, dopamine and uric acid, Sens. Actuators, B, 2016, 227, 488-496.

44 S. A. Alves, L. L. Soares, L. A. Goulart and L. H. Mascaro, Solvent effects on the photoelectrochemical properties of $\mathrm{WO}_{3}$ and its application as dopamine sensor, J. Solid State Electrochem., 2016, 9, 2461-2470.

45 X. L. Wu, L. B. Wang, W. Ma, Y. Y. Zhu, L. G. Xu, H. Kuang and C. L. Xu, A Simple, Sensitive, Rapid and Specific Detection Method for Bisphenol A based on Fluorescence Polarization Immunoassay, Immunol. Invest., 2012, 41, 3850.

46 Z. Z. Fan, L. F. Fan, S. M. Shuang and C. Dong, Highly sensitive photoelectrochemical sensing of bisphenol A based on zinc phthalocyanine/ $\mathrm{TiO}_{2}$ nanorod arrays, Talanta, 2018, 189, 16-23.

47 M. Y. Li, Y. L. Huang, S. Q. Wang, C. Q. Feng, H. M. Wu and H. Mei, Visible light driven photoelectrochemical sensor for chromium(VI) BiOI microspheres decorated with metallic bismuth, Microchim. Acta, 2019, 186, 345. 